\title{
Small Peptide of Soybean Hydrolysate Is Absorbed More Rapidly than Large Peptide in the Perfused Rat Small Intestine
}

\author{
Hwal Chun, ${ }^{*}$ Masaya Sasaki, Yoshihide FujIYAma, \\ and Tadao BAMBA \\ Second Department of Internal Medicine, Shiga University of Medical Science, \\ Otsu 520-2192, Japan
}

(Received March 11, 1998)

\begin{abstract}
Summary The effects of peptide chain length on the absorption of soybean hydrolysates by the rat small intestine were investigated by the perfusion. Two types of soybean hydrolysates, a small peptide (SP; average peptide chain length: 3.2) and a large peptide (LP; average peptide chain length: 5.2), were prepared for this experiment. KrebsRinger phosphate buffer ( $\mathrm{pH} 7.0$ ) containing $0.5 \%(\mathrm{w} / \mathrm{v}$ ) of either of the two types of soybean hydrolysates was perfused through a $15-\mathrm{cm}$ length of rat jejunum for $70 \mathrm{~min}$. After the perfusion, samples were collected; and the total amount of amino acid was then measured by an amino acid analyzer (Hitachi L-8500) after hydrolysis. The absorption rate of each amino acid was subsequently determined. The absorption rate for glycine, alanine, isoleucine, leucine histidine, arginine, phenylalanine, and proline in SP was significantly greater than that for those in LP. The total amino acid absorption of SP was significantly greater than that of LP. There were no significant differences in the net absorption of water in the buffer solutions of SP and LP. We thus concluded that SP is more greatly absorbed than LP in the intestinal perfusion model of the rat small intestine.
\end{abstract}

Key Words: soybean hydrolysate, intestinal perfusion, absorption, peptide chain length

Amino acids are one of the most important elements of enteral nutrition. It has been reported that di- and tripeptides are absorbed more rapidly, and reach a

${ }^{*}$ To whom correspondence should be addressed. 
higher concentration in the bloodstreams than amino acids [1]. We previously reported that small peptides derived from soybean hydrolysates are absorbed more rapidly than large peptides, based on data from experiment using an everted sac model of the rat intestine [2]. Intestinal amino acid transport is regulated in a complicated way by the levels of hydrolyzed protein or amino acids [3, 4], and intestinal amino acid transporters are regulated semi-independently of each other [5]. The brush-border membrane of the small intestine contains several peptidases [6], including amino-oligopeptidase, acidic aminopeptidases, glycyl-leucine peptidase, aspartyl-lysine peptidase, and dipeptidyl aminopeptidase. Among these enzymes, amino-oligopeptidase appears to be most abundant [7], and its affinity for peptides varies according to the number of amino acid residues and the length of amino acid side chains [8]. Although the oligopeptides, which are the products of protein digestion in the gut lumen, may vary in length from 2 to 6 amino acid residues, they are mostly di- and tripeptides [9]. In the present study, we investigated the effect of average peptide chain length on the absorption of soybean hydrolysates by using the intestinal perfusion model in rats.

\section{MATERIALS AND METHODS}

Animals and diets. Five male Wistar rats (250-300 g, Clea, Osaka, Japan) were kept at a room temperature of $25^{\circ} \mathrm{C}$ at $55 \pm 5 \%$ humidity under a 12-h light/ 12-h dark cycle (light: $8.00-20.00 \mathrm{~h}$ ), and were allowed free access to a normal pellet diet (CE-2, Clea) and water.

Two types of soybean peptides. Table 1 shows the composition of the two partial enzymic hydrolysates of soybean (Fuji Seiyu Co., Ltd., Osaka, Japan). Two types of soybean hydrolysates were prepared from a single protein source, and so the amino acid compositions of the hydrolysates were almost identical. The average peptide chain length of soybean peptides was analyzed by determination of $\alpha$-amino nitrogen, before and after total acid hydrolysis [10]. The average peptide chain length was calculated as below:

Average peptide chain length $=$ Average molecular weight of soybean peptides/Average molecular weight of amino acids (after total hydrolysis of soybean peptides)

The average molecular weight of soybean peptides was calculated as below:

Average molecular weight of peptides=Concentration of protein in dilute solution $(\mu \mathrm{g} / \mathrm{ml}) /$ Concentration of peptide in dilute solution $(\mu \mathrm{mol} / \mathrm{ml})$

The concentration of soybean peptide was determined by use of trinitrobenzenesulfonic acid (TNBS) [10]. 
Table 1. Composition of the two types of soybean protein.

\begin{tabular}{crr}
\hline & SP & LP \\
\hline Water (\%) & 4.4 & 2.3 \\
Crude protein/dry (\%) & 90.5 & 88.7 \\
Total sugar/dry (\%) & 4.8 & 4.7 \\
Average peptide chain length & 3.2 & 5.2 \\
\hline Amino acids (\%) & SP & LP \\
\hline Thr & 3.8 & 3.6 \\
Tyr & 3.5 & 3.2 \\
Phe & 5.0 & 4.9 \\
Cys & 1.3 & 1.4 \\
Met & 1.2 & 1.1 \\
Val & 4.4 & 3.9 \\
Ile & 4.4 & 4.0 \\
Leu & 7.2 & 6.9 \\
Lys & 6.4 & 6.4 \\
Trp & 1.2 & 1.1 \\
His & 2.4 & 2.3 \\
Asp & 12.1 & 12.2 \\
Ser & 5.3 & 5.5 \\
Glu & 21.0 & 23.0 \\
Pro & 5.3 & 5.2 \\
Gly & 4.0 & 3.9 \\
Ala & 3.9 & 3.8 \\
Arg & 7.8 & 7.6 \\
\hline
\end{tabular}

SP: small peptide; LP: large peptide.

The average peptide chain length of the small peptide (SP) was 3.2 amino acids; and that of the large peptide (LP), 5.2 amino acids.

Intestinal perfusion and absorption test. Food was withheld overnight, and then the rats were anesthetized with an intraperitoneal injection of pentobarbital $(30 \mathrm{mg} / \mathrm{kg})$. Fifteen-centimeter segments of the intestine distal from the ligament of Treitz in the rats were prepared for the perfusion test. After the jejunum of rat had been exposed, a small incision was made in the jejunum at the Treitz ligament, and then a tube was inserted and fixed to the jejunum with the nylon thread. Next, a small incision was also made in the jejunum $15 \mathrm{~cm}$ from the Treitz ligament toward the anus and another tube was inserted and fixed to the jejunum (thus the length of the intestinal perfusion was $15 \mathrm{~cm}$ ). After these tubes had been fixed to the jejunum, buffer solution was introducted into the tube inserted into the incision in the oral side of the jejunum, perfused through the $15-\mathrm{cm}$ segment of jejunum, and collected from the tube at the anal side.

The perfusion fluid was Krebs-Ringer phosphate buffer containing $0.5 \%$ (w/ v) of SP or LP, and $5 \mathrm{~g} /$ liter of polyethylene glycol 4000 was used as the nonabsorbable volume marker. The fluid was adjusted to a final $\mathrm{pH}$ of 7.0 , and the temperature of the fluid was maintained at $37^{\circ} \mathrm{C}$.

Vol. 26, No. 3, 1999 
First, the SP- or LP-(randomly allocated) containing solution was perfused at $0.38 \mathrm{ml} / \mathrm{min}$ for $70 \mathrm{~min}$. Next, a second perfusion was performed with the other peptide solution at the same rate for the same period of time. The intestinal perfusate was then replaced with the first solution, and the perfusion was repeated (third perfusion). The perfusate fractions were collected at 10-min intervals. After treatment with trichloroacetic acid, $0.6 \mathrm{ml}$ of $10 \mathrm{~N} \mathrm{HCl}$ was added to each of the 0.4-ml samples; and the samples were hydrolyzed at $110^{\circ} \mathrm{C}$ for $24 \mathrm{~h}$ for the amino acid analysis. The amino acid composition of the solution was analyzed with an automatic amino acid analyzer (Hitachi L-8500, Hitachi, Tokyo, Japan), and the absorption rate for each peptide was calculated from the standard formula described below [11]:

$$
\begin{gathered}
\text { Solute absorption }=V \times\left(S_{\mathrm{i}}-S_{\mathrm{d}} \times \mathrm{PEG}_{\mathrm{i}} / \mathrm{PEG}_{\mathrm{d}}\right) \text {, where: } \\
V=\text { infusion rate } \\
S_{\mathrm{i}}=\text { infused concentration of solute } \\
S_{\mathrm{d}}=\text { solute concentration in the distal samples } \\
\mathrm{PEG}_{\mathrm{i}}=\text { infused concentration of } \mathrm{PEG} \\
\mathrm{PEG}_{\mathrm{d}}=\mathrm{PEG} \text { concentration in the distal sample }
\end{gathered}
$$

The absorption rate was expressed as the mean of five consecutive fractions, collected 10 min or more after the beginning of each perfusion, when the rate had become stabilized. As the absorption rate of the first and third perfusions were almost the same, a mean value of the first and third perfusions was calculated.

The concentration of polyethylene glycol (PEG) was determined by the method of Malawer [12].

Tryptophan was excluded from consideration because of its massive destruction upon acid hydrolysis [13]. Serine and threonine were also excluded from consideration because of their destruction upon acid hydrolysis.

The net absorption of water was also determined by use of a standard formula.

Statistical analysis. The results were expressed as the mean \pm SEM. Statistical comparisons were performed with Student's $t$-test. A $p$ value of less than 0.05 was considered to be statistically significant.

\section{RESULTS}

\section{Absorption of neutral amino acids}

The absorption rates for glycine, alanine, isoleucine, and leucine in the SP were significantly greater than those for these amino acids in the LP (Fig. 1). There was no significant difference in absorption rate for valine.

\section{Absorption of basic amino acids}

The absorption rates for histidine and arginine in the SP were significantly greater than those for these amino acids in the LP (Fig. 2). There was no 


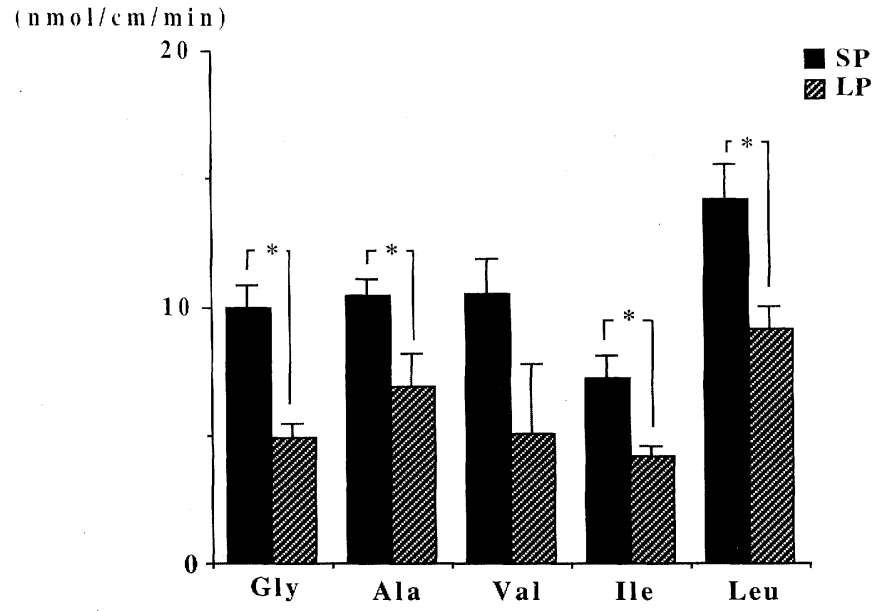

Fig. 1. Absorption of neutral amino acids in the two types of soybean peptides in the rat jejunal perfusion model. SP: small peptide; LP: large peptide. Each point represents the means \pm SEM. $n=5 .{ }^{*} p<0.05$ : significant difference between the rate of absorption of SP and that of LP.

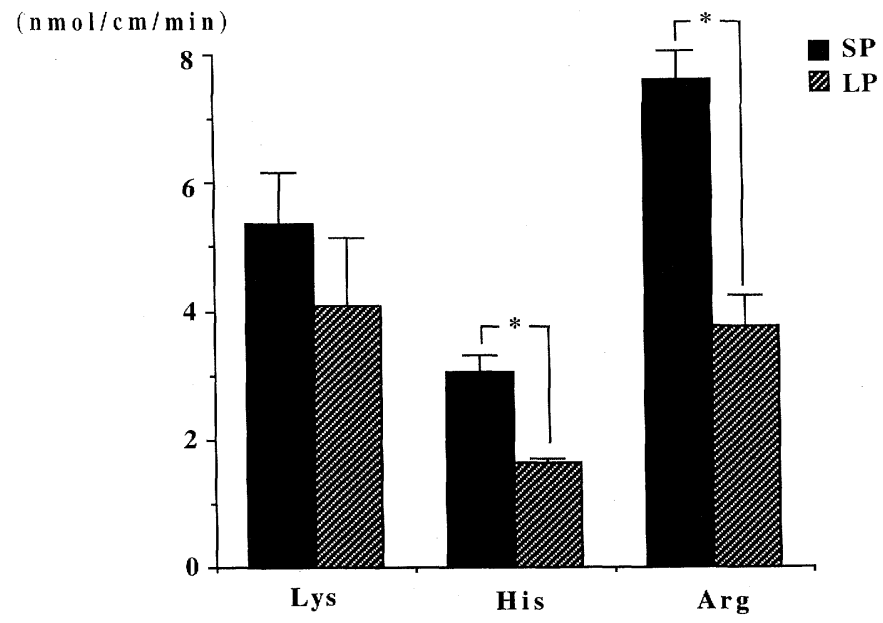

Fig. 2. Absorption of basic amino acids in the two types of soybean peptides in rat jejunal perfusion model. SP: small peptide; LP: large peptide. Each point represents the means \pm SEM. $n=5 .{ }^{*} p<0.05$ : significant difference between the rate of absorption of SP and that of LP.

significant difference in absorption rate for lysine between SP and LP.

Absorption of aromatic amino acids and proline

Phenylalanine and proline in the SP showed a significantly greater absorption

Vol. 26, No. 3, 1999 
rate than those in the LP (Fig. 3), but there was no significant difference in absorption rate for tyrosine.

\section{Absorption of total amino acids}

The total amino acid absorption of SP was significantly greater than that of the LP by a ratio of 1.47 to 1 (Fig. 4).

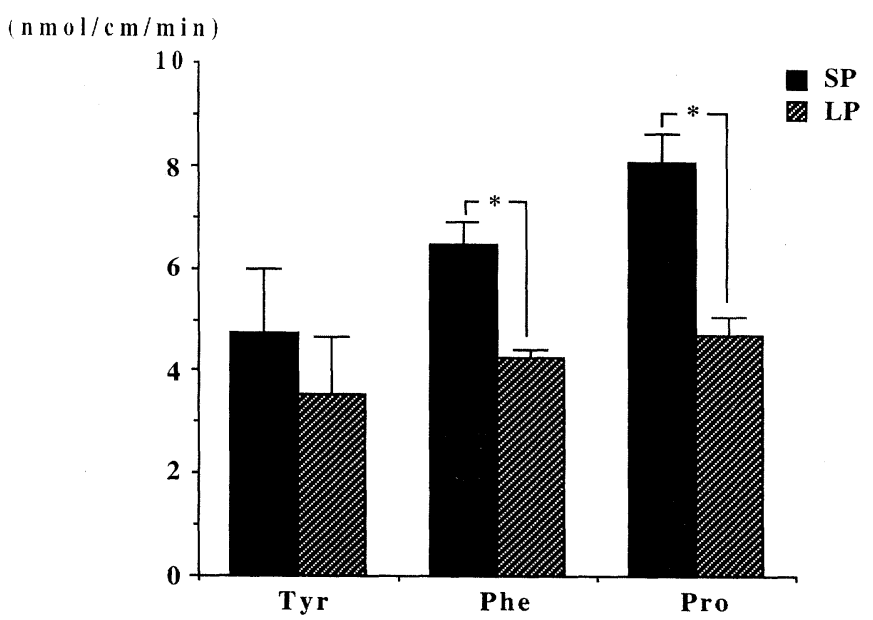

Fig. 3. Absorption of tyrosine, phenylalanine, and proline in the two types of soybean peptides in the rat jejunal perfusion model. SP: small peptide; LP: large peptide. Each point represents the means \pm SEM. $n=5 .{ }^{*} p<0.05$ : significant difference between the rate of absorption of SP and that of LP.

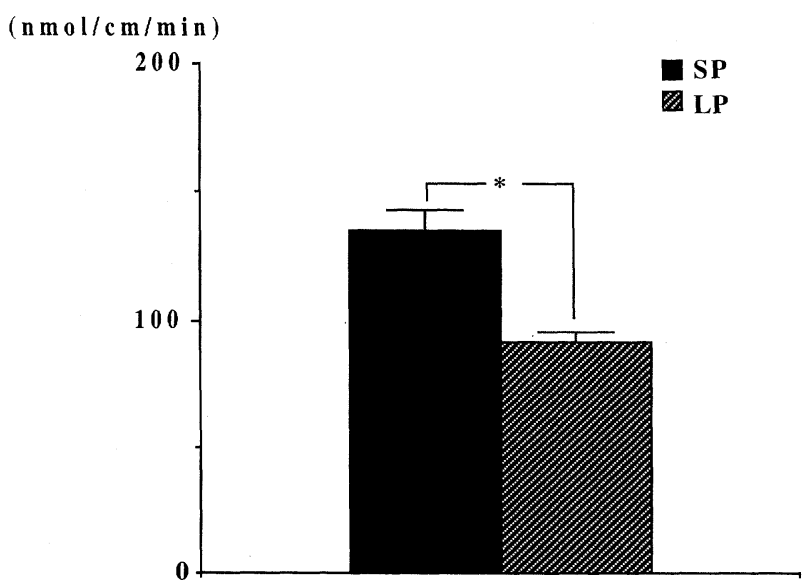

Fig. 4. Total absorption of amino acids in the two types of soybean peptides in the rat jejunal perfusion model. SP: small peptide; LP: large peptide. Each point represents the mean \pm SEM. $n=5 .{ }^{*} p<0.05$ : significant difference between amount of absorption of the SP and that of LP.

J. Clin. Biochem. Nutr. 


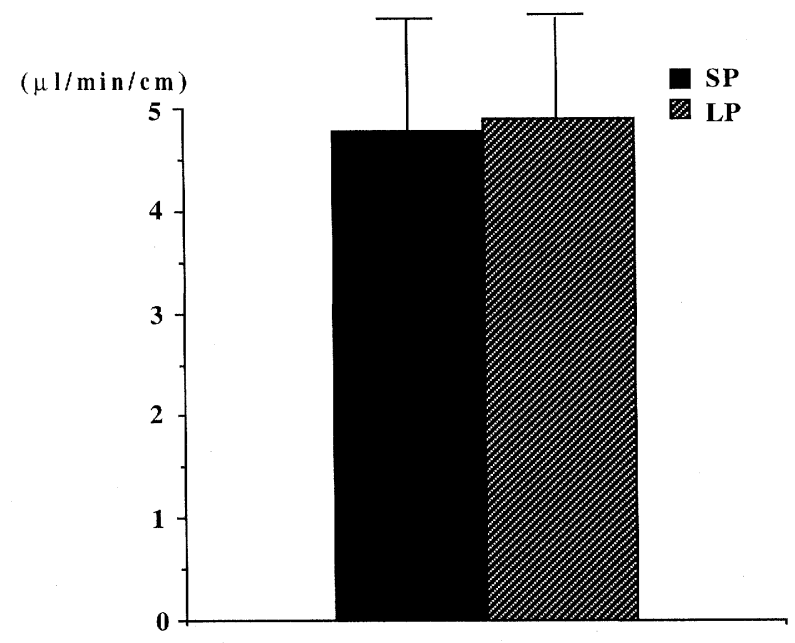

Fig. 5. Net water absorption in each buffer containing the two types of soybean peptides in the rat jejunal perfusion model. SP: small peptide; LP: large peptide. Each point represents the means \pm SEM. $n=5$.

Net absorption of water

There was no significant difference in the net absorption of water in the buffers of SP and LP (Fig. 5).

\section{DISCUSSION}

In this experiment, intestinal perfusion was used to determine the absorption rate of soybean peptide. The intestinal perfusion is an experiment in vivo and differs from the absorption experiment in vitro using an everted rat intestinal sac, with which we previously reported the relationship between peptide absorption and intact transport of peptides [2]. There is no blood circulation in the intestinal mucosa in the everted intestinal sac, because the intestine is removed from the mesenteric vessels. Since there is no blood circulation, the absorption experiment using everted intestinal sac may not last several hours. In our previous experiment using the everted intestinal sac, the samples were collected after 5 or $10 \mathrm{~min}$ of incubation of the sac [2]. In this present experiment using intestinal perfusion, although jejunal perfusion was made, the mesenteric vessels were maintained. Thus, there was blood flow in the intestinal mucosa, and the absorption rate determined from this perfusion experiment should more accurately reflect the feature of absorption of soybean hydrolysates in vivo. The present results indicated that SP is absorbed more rapidly than LP in rat jejunal perfusion in vivo.

The nutritional importance of the dipeptide transport system is suggested by intestinal perfusion studies demonstrating that many amino acids are absorbed 
faster as dipeptides than as free amino acids. However, the relative physiologic importance of free amino acid versus di- and tripeptide transport in vivo remains unclear [14-16].

We previously reported that SP was absorbed more rapidly than LP due to the greater transport of intact peptides, based on findings made by using the everted sac model of rat intestine [2]. In the present study, the absorption rates of various peptides containing neutral, basic, and aromatic amino acids in the SP were greater than those in the LP, and the increase did not seem to be dependent on the specific amino acid carrier. The optimal length of oligopeptides preferred by PepT1, which is a $\mathrm{H}^{+}$-coupled transporter of oligopeptides, was studied earlier by use of oligomers of glycine $\left(\mathrm{Gly}_{n} ; n=1-5\right)$, and the glycine dimer had the optimal length of oligopeptides [17]. The present results indicate that the average peptide chain length influences the absorption rate of many amino acids in the soybean hydrolysate but that it does not affect the net water absorption.

When an elemental diet is used clinically by enteral nutrition, one of the major complications is diarrhea [18]. Electrolyte secreted into the lumen of the small intestine in response to the administration of hypertonic diets is thought to be a major factor in the pathogenesis of the diarrhea. Since protein hydrolysates are less hypertonic than free amino acid mixtures, the use of a peptide formula as the nitrogen source would seem to be one of the methods for reducing diarrhea in patients under enteral nutrition therapy.

The absorption experiment with intestinal perfusion may reflect more clinical aspects than that with the everted sac intestine. It is reported that the oligopeptide transport system of the small intestine is resistant to mucosal injury [19]. These results indicate that small peptides, which consist of mainly di- and tripeptides, are absorbed more rapidly than large peptides and that small peptides are useful as the nitrogen source for enteral nutrition.

We thank Noboru Urushiyama for assistance with amino acid analysis. This work was partially supported by Fuji Seiyu Company.

\section{REFERENCES}

1. Claft, I.L., Deddes, D., and Matthews, D.M. (1968): Absorption and malabsorption of glycine and glycine peptides in man. Gut, 9, 425-437.

2. Chun, H., Sasaki, M., Fujiyama, Y., and Bamba, T. (1996): Effect of peptide chain length on absorption and intact transport of hydrolyzed soybean peptide in rat everted intestinal sac. J. Clin. Biochem. Nutr., 21, 131-140.

3. Karasov, W.H., Solberg, D.H., Chan, S.D., Hughes, M., Stein, E.D., and Dimond, J.M. (1985): Is intestinal transport of sugars and amino acids subject to critical-period programming? Am. J. Physiol., 249, G770-785.

4. Karasov, W.H., Solberg, D.H., and Dimond, J.M. (1987): Dependence of intestinal amino acid uptake on dietary protein or amino acid levels. Am. J. Physiol, 252, G614-625.

5. Stein, E.D., Chan, S.D., and Dimond, J.M. (1987): Comparison of different dietary amino acids as inducers of intestinal amino acid transporters. Am. J. Physiol., 252, G626-635.

6. Tobey, N., Heizer, W., and Yeh, R. (1985): Human intestinal brush border peptidases. 
Gastroenterology, 88, 913-926.

7. Adibi, S.A., and Kim, Y.S. (1981): Peptide absorption and hydrolysis, in Physiology of the Gastrointestinal Tract, ed. by Johnson, L.R., Raven Press, New York, pp. 1073-1095.

8. Kania, R.K., Santiago, N.A., and Gray, G.M. (1977): Intestinal surface amino-oligopeptidases. Substrate kinetics and topography of the active site. J. Biol. Chem., 252, 4929-4934.

9. Adibi, S.A., and Mercer, D.W. (1973): Protein digestion in human intestine as reflected in luminal, mucosal, and plasma amino acid concentration after meals. J. Clin. Invest., 52, 1586-1594.

10. Habeeb, A.F.S.A. (1966): Determination of free amino groups in proteins by trinitrobenzensulfonic acid. Anal. Biochem., 14, 328-336.

11. Modigliani, R., and Bernier, J.J. (1971): Absorption of glucose, sodium, and water by the human jejunum studied by intestinal perfusion with a proximal occluding balloon and at variable flow rates. Gut, 12, 184-193.

12. Malawer, S.J., and Powell, D.W. (1967): An improved turbidimetric analysis of polyethylene glycol utilizing an emulsifier. Gastroenterology, 53, 250-256.

13. Gardner, M.L.G., Lindblad, B., Burston, D., and Matthews, D.M. (1983): Transmucosal passage of intact peptides in the guinea-pig small intestine in vivo: A reappraisal. Clin. Sci., 64, 433-439.

14. Matthews, D.M. (1975): Intestinal absorption of peptides. Physiol. Rev., 55, 537-608.

15. Silk, D.B.A., Hegarty, J.E., Fairclough, P.D., and Clark, M.L. (1982): Characterization and nutritional significance of peptide transport in man. Ann. Nutr. Metab., 26, 337-352.

16. Rosen-Levin, E.M., Smithson, K.W., and Gray, G.M. (1980): Complementary role of surface hydrolysis and intact transport in the intestinal assimilation of di- and tripeptides. Biochim. Biophys. Acta, 629, 126-134.

17. Fei, Y., Kanai, Y., Nussberger, S., Ganapathy, V., Leibach, F.H., Romero, M.F., Singh, S.K., Boron, W.F., and Hediger, M.A. (1994): Expression cloning of a mammalian protoncoupled oligopeptide transporter. Nature, 368, 563-566.

18. Heizer, W.D., and Holcombe, B. (1991): Enteral nutrition (tube feeding), in Textbook of Gastroenterology, ed. by Yamada, T., J.B. Lippincott Company, Philadelphia, PA, pp. 975984.

19. Tanaka, H., Miyamoto, K.I., Morita, K., Haga, H., Segawa, H., Shiraga, T., Fujioka, A., Kouda, T., Taketani, Y., Hisano, S., Fukui, Y., Kitagawa, K., and Takeda, E. (1998): Regulation of the PepT1 peptide transporter in the rat small intestine in response to 5-fluorouracil-induced response. Gastroenterology, 114, 714-723. 